\title{
Imaging the delayed complications of childhood Kawasaki
}

\section{disease [version 1; peer review: 1 approved, 2 approved with}

\section{reservations]}

\author{
Andrew Crean (iD), Lee Benson (1D2), Ashish Shah³, Kelly Han4, John Lesser5, \\ Brian W. McCrindle ${ }^{2}$ \\ ${ }^{1}$ Cardiology, University of Ottawa Heart Institute, Ottawa, ON, K1Y 4W7, Canada \\ ${ }^{2}$ Cardiology, Hospital for Sick Children, Toronto, ON, M5G 1X8, Canada \\ ${ }^{3}$ Cardiology, St Boniface Hospital, Winnipeg, Manitoba, R2H 2A6, Canada \\ ${ }^{4}$ Cardiology, Children's Minnesota Hospital, Minneapolis, MN, 55404, USA \\ ${ }^{5}$ Cardiology, Minneapolis Heart Institute, Minneapolis, MN, 55407, USA
}

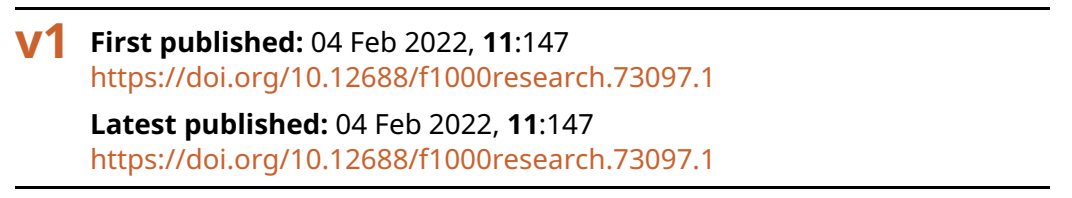

\section{Abstract}

This review will discuss the long-term complications of Kawasaki disease with a particular focus on imaging surveillance of the coronary arteries in adolescence and adult life. The relative advantages and disadvantages of each modality will be illustrated with practical examples, demonstrating that, in many cases, a multimodality imaging strategy may be required.

\section{Keywords}

Kawasaki disease, cardiovascular magnetic resonance, CMR, cardiac $\mathrm{CT}$, positron emission tomography, $\mathrm{PET}$, intravascular ultrasound, IVUS, optical coherence tomography, OCT

\section{Open Peer Review \\ Approval Status ? ? \\ 12 \\ 23

version $1 ?$ ?

04 Feb 2022 view view view \\ 1. Diana van Stijn ID, Amsterdam UMC, University of Amsterdam, Amsterdam, The Netherlands \\ 2. Kai Sheng Hsieh, China Medical University, Taichung, Taiwan \\ 3. Rakesh Kumar Pilania , Institute of
Medical Education and Research, Chandigarh,
India}

Any reports and responses or comments on the article can be found at the end of the article. 
Corresponding author: Andrew Crean (andrewcrean@gmail.com)

Author roles: Crean A: Conceptualization, Methodology, Project Administration, Supervision, Writing - Original Draft Preparation, Writing - Review \& Editing; Benson L: Conceptualization, Data Curation, Writing - Original Draft Preparation, Writing - Review \& Editing; Shah A: Conceptualization, Project Administration, Supervision, Writing - Original Draft Preparation, Writing - Review \& Editing; Han K: Writing - Original Draft Preparation, Writing - Review \& Editing; Lesser J: Writing - Original Draft Preparation, Writing - Review \& Editing; McCrindle BW: Conceptualization, Methodology, Supervision, Writing - Original Draft Preparation, Writing - Review \& Editing Competing interests: No competing interests were disclosed.

Grant information: The author(s) declared that no grants were involved in supporting this work.

Copyright: $\odot 2022$ Crean A et al. This is an open access article distributed under the terms of the Creative Commons Attribution License, which permits unrestricted use, distribution, and reproduction in any medium, provided the original work is properly cited.

How to cite this article: Crean A, Benson L, Shah A et al. Imaging the delayed complications of childhood Kawasaki disease [version 1; peer review: 1 approved, 2 approved with reservations] F1000Research 2022, 11:147

https://doi.org/10.12688/f1000research.73097.1

First published: 04 Feb 2022, 11:147 https://doi.org/10.12688/f1000research.73097.1 


\section{Introduction}

Kawasaki disease (KD) is a systemic vasculitis of unknown etiology. Coronary arterial complications, both in acute or chronic phase of the illness, result in high morbidity and mortality.

Vascular remodeling characterized by fibroblastic proliferation and matrix metalloproteinase deposition results in progressive fibrosis and, eventually, stenosis. ${ }^{1}$ The flow pattern in an aneurysmal segment is characterized by recirculation, reduced wall shear stress and stasis, whereas there is flow acceleration through stenotic lesions. ${ }^{2}$ Such flow alterations result in platelet activation, which, in the presence of endothelial dysfunction, creates a highly thrombogenic milieu, and may result in thrombotic occlusion of the coronary arteries. ${ }^{3}$

Although aneurysmal coronary artery dilatation is seen initially in pediatric acute $\mathrm{KD}$, the subsequent complications of aneurysm thrombosis, distal embolism and infarction, or inter-aneurysm coronary artery stenosis, are more often seen much later in life. As a result, the sufferer of childhood KD will require life-long surveillance throughout adulthood in those cases where coronary artery dilatation fails to regress in the convalescent period. This review will describe these complications and offer suggestions to guide the selection of imaging modality (Table 1), through discussion of each in turn.

\section{Echocardiography}

Echocardiography is always the initial tool in the assessment of the patient with Kawasaki disease. Young children generally have excellent echocardiographic windows with the proximal portions of the coronary arteries being fully visualized. Imaging features to note include coronary artery dilatation (which on occasion may be subtle); ectasia and lack of distal tapering; frank aneurysmal formation; and perivascular echogenicity or "brightness" due to inflammation of the arterial wall (in acute presentations). Aneurysms may be isolated or segmental with intervening 'skip areas' of normal vessel and they may be either saccular or fusiform in shape. Proximal aneurysms can be accurately measured and evaluated for internal thrombosis or occlusion (Figure 1).

The examination should also include a formal evaluation of cardiovascular function. Acutely unwell patients frequently have an associated myocarditis and may have wall motion abnormalities on $2 \mathrm{D}$ or 3D imaging. Associated pericarditis may present with pericardial effusion. Myocardial deformation tracking using speckle tracking may demonstrate improvement early in the recovery period, ahead of global measures such as ejection fraction, ${ }^{4}$ but may also remain abnormal in the long term, especially in more severely affected patients. 5

Acute coronary artery thrombosis, usually the result of in situ thrombosis within an aneurysm, may result in myocardial infarction or stunning and profound regional wall motion abnormality. Similarly, distal embolization of thrombus within an aneurysm may lead to myocardial infarction, wall motion abnormality and eventually regional thinning.

Valvular involvement in Kawasaki disease is reported but is rarely a prominent feature. Nonetheless the presence of severe mitral regurgitation should raise the question of underlying myocardial ischemia and secondary papillary muscle dysfunction.

\section{Nuclear perfusion imaging}

Nuclear medicine techniques were, for a long time, the mainstay of non-invasive imaging in Kawasaki disease for the detection of flow-limiting lesions and infarction (Figure 2). The ready availability of SPECT equipment together

Table 1. Relative strengths and weaknesses of commonly-used imaging modalities for Kawasaki disease.

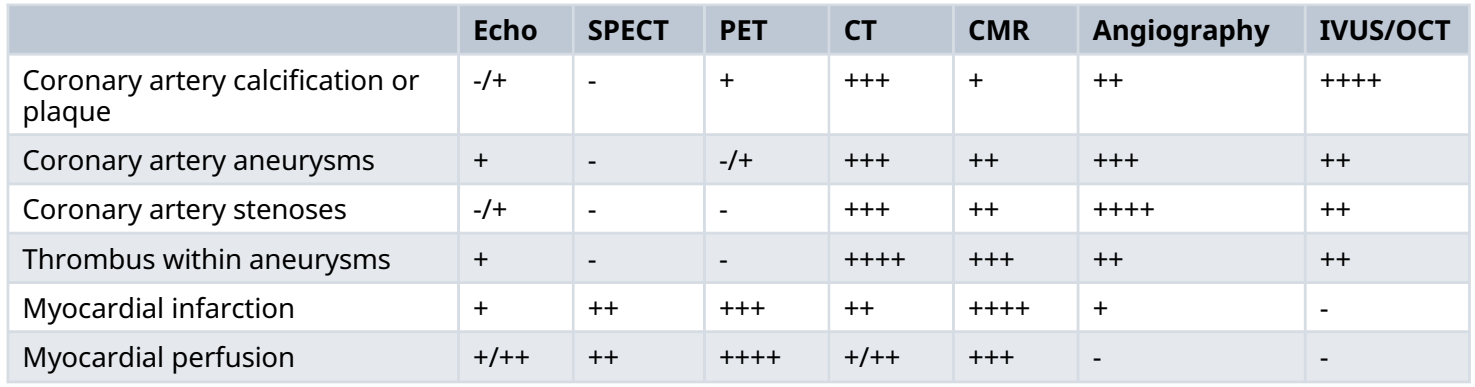

SPECT, single photon emission computed tomography; CT, computed tomography; PET, positron emission tomography; CMR, cardiovascular magnetic resonance; IVUS, intravascular ultrasound; OCT, optical coherence tomography. 


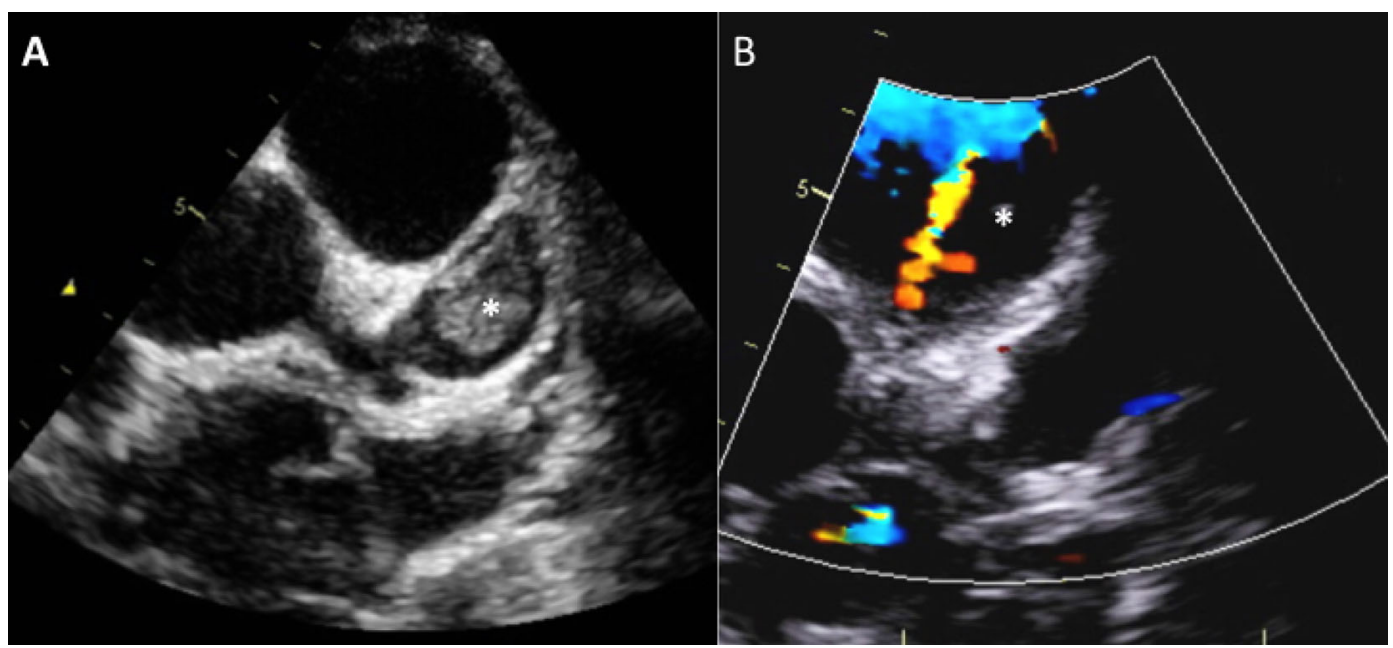

Figure 1. Evidence of acute thrombus in LAD seen on echocardiography. A) Thrombus (asterisk) within the proximal portion of the large LAD aneurysm. B) Accelerating narrowed diastolic flow jet around the peripheral rim of the thrombus. LAD, left anterior descending.

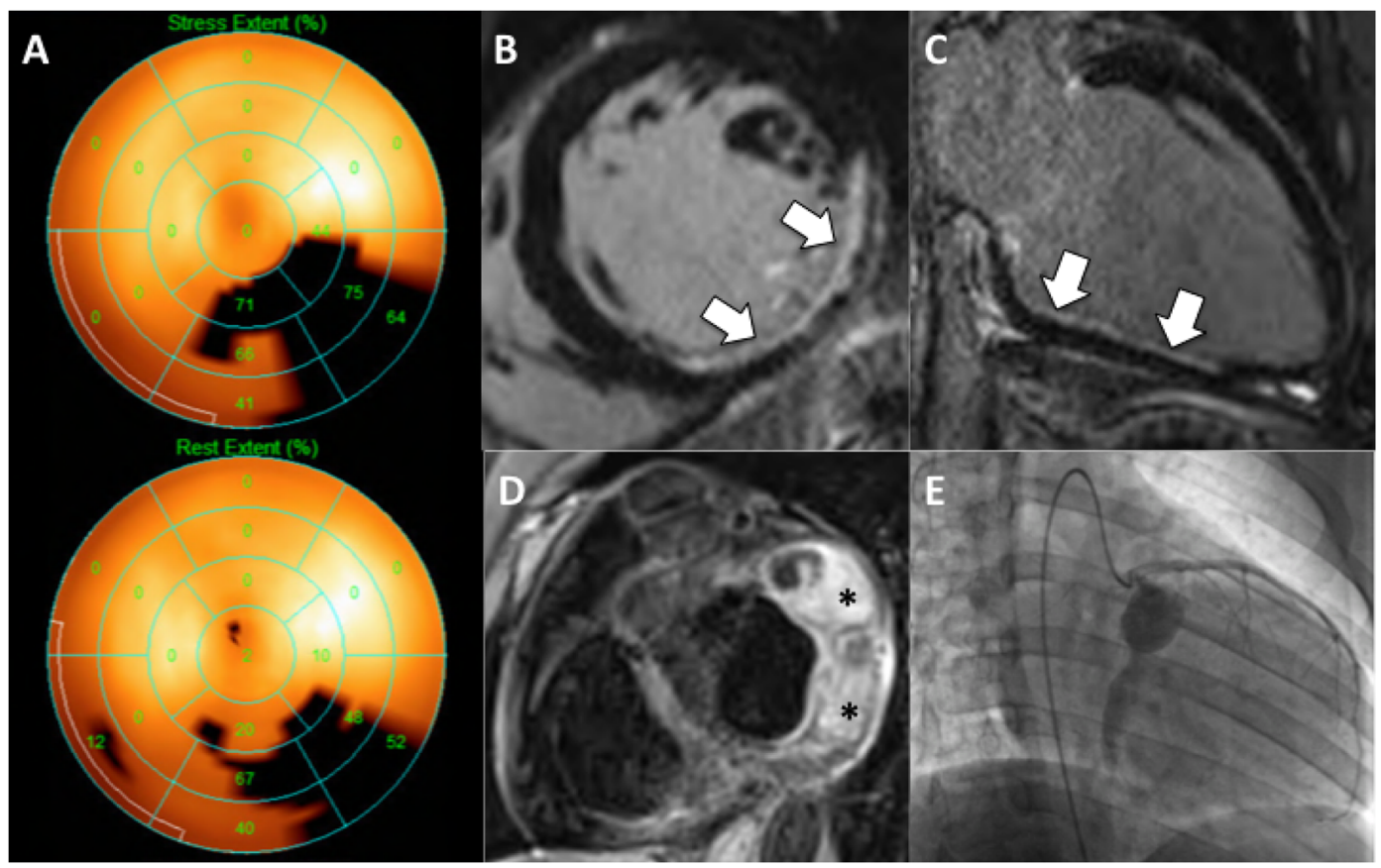

Figure 2. Circumflex territory infarct. A) Nuclear SPECT perfusion study demonstrating a largely fixed infero-lateral defect on polar map. B,C) Late gadolinium enhancement reveals a non-transmural scar (white arrows) in the same area. D) Black-blood CMR shows circumflex aneurysms with thrombus (asterisks). E) Angiogram confirms CX aneurysms with poor distal flow.

with the ability to combine perfusion and treadmill imaging has made this, historically, the most widely used approach to following patients in the chronic phase, both before and after coronary artery bypass surgery. ${ }^{6}$ There are no data in a sufficiently large sample from which to derive diagnostic accuracy estimates of stress SPECT; however, the ability of young people to exercise to high levels together with (generally) lower body mass index, and hence less photon attenuation, compared with the elderly atherosclerotic population, may lead to fewer non-diagnostic or false positive studies. Nonetheless, there are strong arguments for following younger patients by alternative means that do not expose them recurrently to ionizing radiation, such as stress echo and stress CMR. 
Nuclear cardiology has, however, provided insights into Kawasaki disease, particularly from positron emission tomographic (PET) imaging - which can provide higher accuracy for disease detection than SPECT perfusion imaging, and with lower radiation exposure. ${ }^{7,8}$ It has been known for a number of years that coronary endothelial function is abnormal following Kawasaki disease. One early paper examined coronary vasodilatory function in patients who had had Kawasaki disease but without any overt coronary involvement, and compared resting and stress flow to that in normal age-matched controls. Resting flow, measured using ${ }^{13} \mathrm{~N}$-ammonia, was comparable in both groups, but interestingly the Kawasaki group had lower levels of hyperemic stress flow (and hence reduced flow reserve) despite ostensibly normal coronary arteries, possibly due to increased microvascular dysfunction. ${ }^{9}$ Hauser et al. demonstrated similar findings in children with normal epicardial arteries after the onset of Kawasaki disease. ${ }^{10}$ These observations were extended by Furuyama et al. who demonstrated similar findings, using ${ }^{15} \mathrm{O}$ PET, in Kawasaki patients with regressed aneurysmal dilatation; but, using the cold pressor test to generate hyperemia, additionally showed impairment of the endothelial-dependent pathway. ${ }^{11}$ A more recent small study demonstrated even greater impairment of endothelialdependent vasodilatation (as assessed by cold pressor test) in patients with frank aneurysmal dilation compared to those with regressed aneurysms, arguing for a gradation of endothelial damage across the spectrum of disease. ${ }^{12}$

Rubidium-82 generators have now been available for several years and this tracer might be an additional clinical tool to assess further the myocardial blood flow metrics on dynamic PET. There are, as yet, no reports of myocardial blood flow assessment using ${ }^{82} \mathrm{Rb}$ in Kawasaki disease.

\section{Cardiovascular magnetic resonance (CMR)}

CMR is arguably the single most useful non-invasive modality for following patients from the age of 8 years and upwards. The strength of CMR lies in the multiplicity of techniques available for assessing structure, function, and tissue characterization.

Stress perfusion MRI is increasingly being performed in congenital and inflammatory coronary conditions. ${ }^{13-15}$ The overall diagnostic accuracy has not been adequately established for non-atherosclerotic coronary conditions, but based on data from the CEMARC study is likely to be higher than for SPECT. ${ }^{16}$ Most centers currently interpret stress CMR images qualitatively (Figure 3). Interestingly, quantitative perfusion CMR has demonstrated abnormalities of

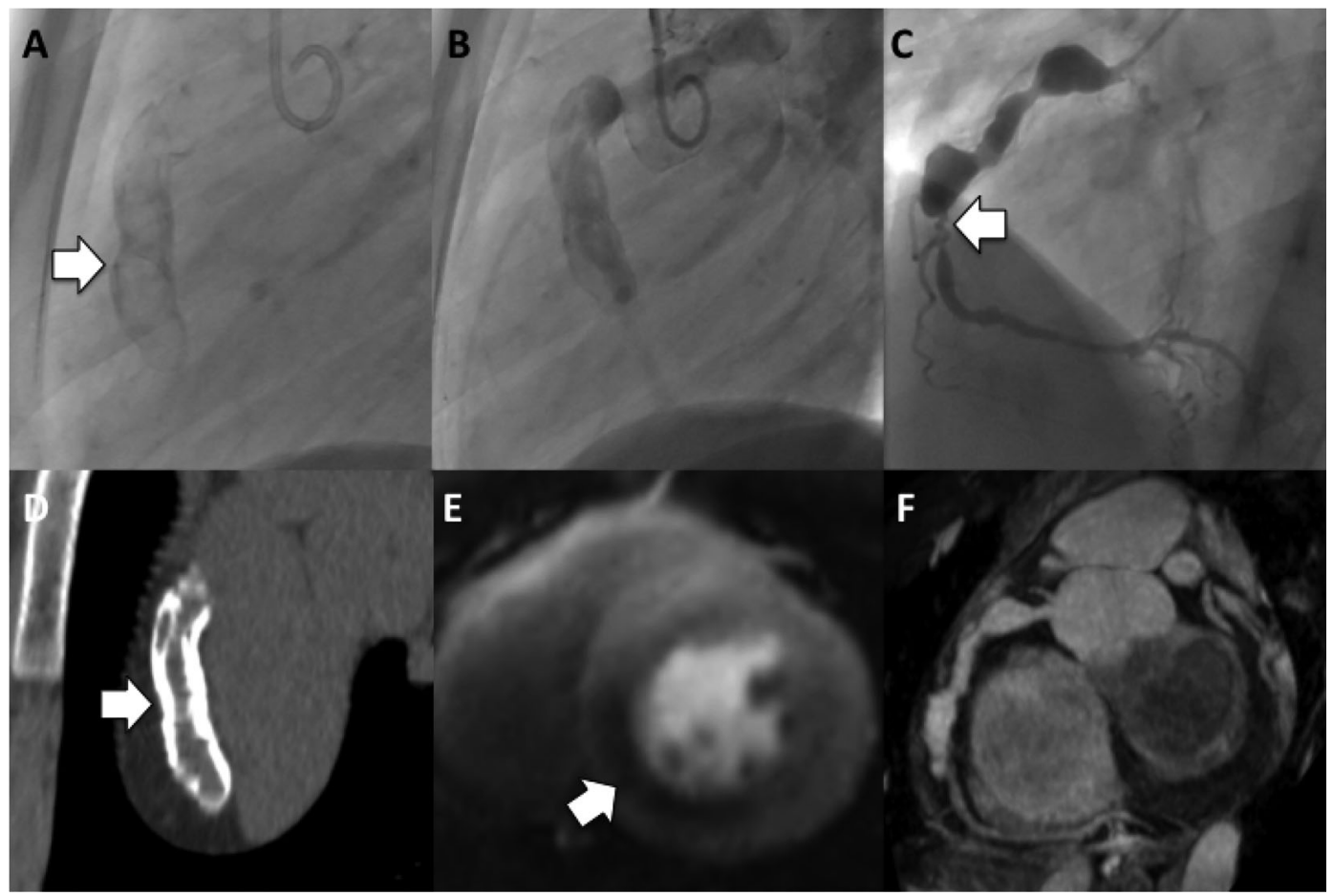

Figure 3. Stress perfusion CMR in right coronary artery stenosis. A,D) Calcific cast of RCA (arrow) is noted prior to contrast injection. B,C) Note that the contrast column does not touch the vessel edge outlined by the calcium, consistent with the presence of laminar thrombus. A focal tight mid RCA stenosis is present (arrow). E) Area of hypoperfusion (arrow) in the basal infero-septum on dipyridamole stress CMR. F) Whole heart coronary MRA of RCA corresponding to image in $\mathrm{C}$ - there is good correlation for aneurysm morphology, but note that the RCA distal stenosis is less well visualized due to inferior spatial resolution of CMR compared to conventional angiography. 

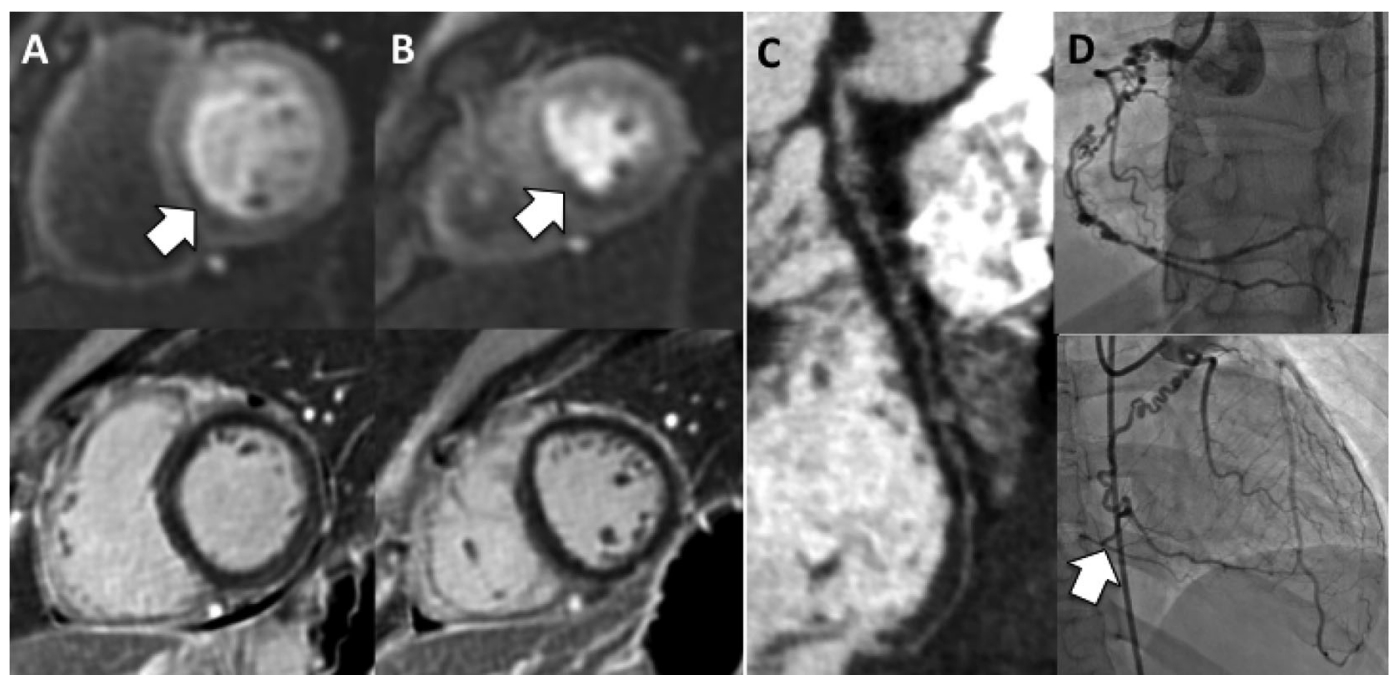

Figure 4. Stress perfusion CMR in the context of collateralization. A,B) A zone of subendocardial hypoperfusion is evident in the RCA territory (arrows, top panels). Note the lack of underlying scar on the corresponding LGE images (bottom panels). C) Cardiac CTA shows a long segment of irregular and hypo-enhanced RCA suspicious for diffuse disease with high-grade stenoses. D) Coronary angiography in fact shows RCA occlusion with extensive bridging collaterals from proximal to distal RCA forming a 'woven' vessel. Further collateralization is seen from the Cx to the distal RCA (arrow, bottom panel). Extensive collateralization like this may reduce the size of the perfusion defect (as here) and the true ischemic burden can be difficult to judge. This young woman wished to get pregnant and went ahead without revascularization after Bruce protocol treadmill stress echo where she managed 13 METS of activity without symptoms, ECG changes or wall motion abnormality.

microvascular function, which is entirely concordant with the available PET literature. ${ }^{16}$ Nonetheless, qualitative perfusion imaging in Kawasaki Disease can be problematic, as extensive collateral networks may form and, even in the setting of total occlusion, perfusion can appear qualitatively normal. It is for this reason that we usually combine cardiac CT and CMR in our practice (Figure 4).

It should be recognized that inducible perfusion defects may be evident even after coronary artery bypass surgery, as incomplete revascularization is often inevitable.

Late gadolinium enhancement (LGE) imaging provides clear images of scarred and infarcted segments due to prior coronary occlusion and/or embolism (Figure 5). The technique is recognized as being highly sensitive for even very small volumes of scar.

Less well-appreciated is the value of LGE imaging for detecting intra-coronary thrombus. Patients with giant aneurysms have altered rheology and altered wall characteristics; furthermore, abnormal shear forces may adversely affect platelets. Therefore all three components of Virchow's triad are often present. Large occlusive thrombus is rarely a difficult diagnosis since the presentation is usually one of acute myocardial infarction. Smaller amounts of thrombus can be quite challenging to visualize and are often missed by echo, as they usually line the walls of an aneurysm without causing much reduction in internal diameter or disrupting flow. The LGE technique provides excellent visualization of ventricular thrombi due to the low signal returned from thrombus contrasting well with the grey/white signal from the coronary blood pool (Figure 5).

\section{Cardiac CT}

Cardiac CT is a useful and reasonable method for 'staging' new referrals to the adult Kawasaki clinic. In our clinic it is a baseline test to establish the presence and extent of aneurysmal disease and stenosis and may act as a gatekeeper to subsequent coronary angiography.

The major advantages of cardiac CT are its rapidity, spatial resolution, and sensitivity for calcium. Modern scanners can complete acquisition of the target anatomy in a few seconds (or less) making CT very suitable for the restless or claustrophobic. Spatial resolution is in the region of $0.5 \mathrm{~mm}$ for most scanners which is adequate for the depiction of aneurysms, thrombus and normal or ectatic coronary segments. Clinically useful coronary coverage is almost invariably 


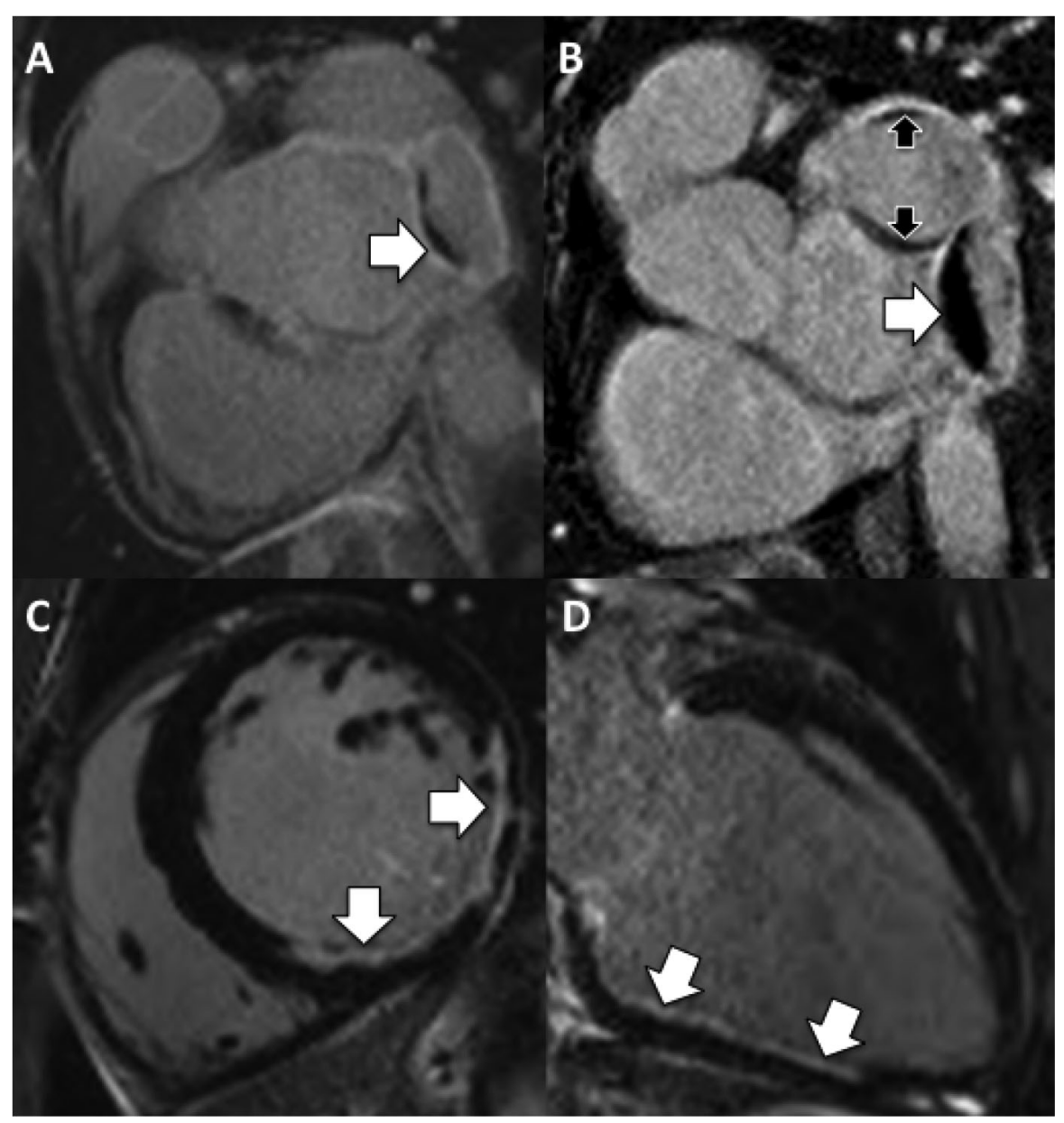

Figure 5. Progressive thrombus deposition in Kawasaki aneurysms. A) Late gadolinium enhancement (LGE) acquired in 2010 demonstrates a small rim of thrombus (arrow) in the more distal of 2 sequential Cx aneurysms. B) Repeat in LGE in 2012 reveals increased thrombus burden in this aneurysm (white arrow) and new layers of thrombus in the more proximal aneurysm (black arrows). The patient had not been compliant with anticoagulation during this period. C \& D) Mid ventricular short-axis and 2-chamber LGE sequences demonstrate partial thickness infarction (arrows) in the basal to mid inferior and inferolateral walls extending into the inferoseptal wall related to embolism into this dominant circumflex coronary artery.

greater by CT than it is by echo ${ }^{17}$ and good correlation with conventional coronary angiography has been demonstrated ${ }^{18}$ (Figure 6).

Unlike CMR, cardiac CT is exquisitely sensitive for even small amounts of calcium. Calcium seems to be mainly associated with aneurysms and in patients above the age of ten. ${ }^{19}$ It is uncertain whether this matters, as it remains unclear whether Kawasaki patients have increased propensity to develop accelerated atherosclerotic lesions as they get older. Occasionally, however, calcification may occur at the site of minimal coronary dilatation, presumably secondary to healing following immune-mediated vasculitis (Figure 7).

Cardiac CT may also be used to identify intra-aneurysmal thrombus. ${ }^{20}$ A delayed phase data set acquired roughly 60 seconds after injection is required in addition to the arterial phase coronary acquisition, to permit full mixing of iodine with blood, which may be delayed in larger aneurysms, leading to filling defects and pseudo-thrombus (Figure 10).

Myocardial scar, due to infarction or embolism, may also be recognized when late iodine enhancement imaging is performed with care. This is, however, an area where CMR retains superiority.

Finally vasodilator stress CT has demonstrated incremental benefit in identification of flow-limiting disease in adult atherosclerotic disease. ${ }^{21}$ There are no published data on this technique in Kawasaki disease, though it could be attractive in theory due to benefits derived from perfectly co-registered anatomy and perfusion data sets (Figure 8). 


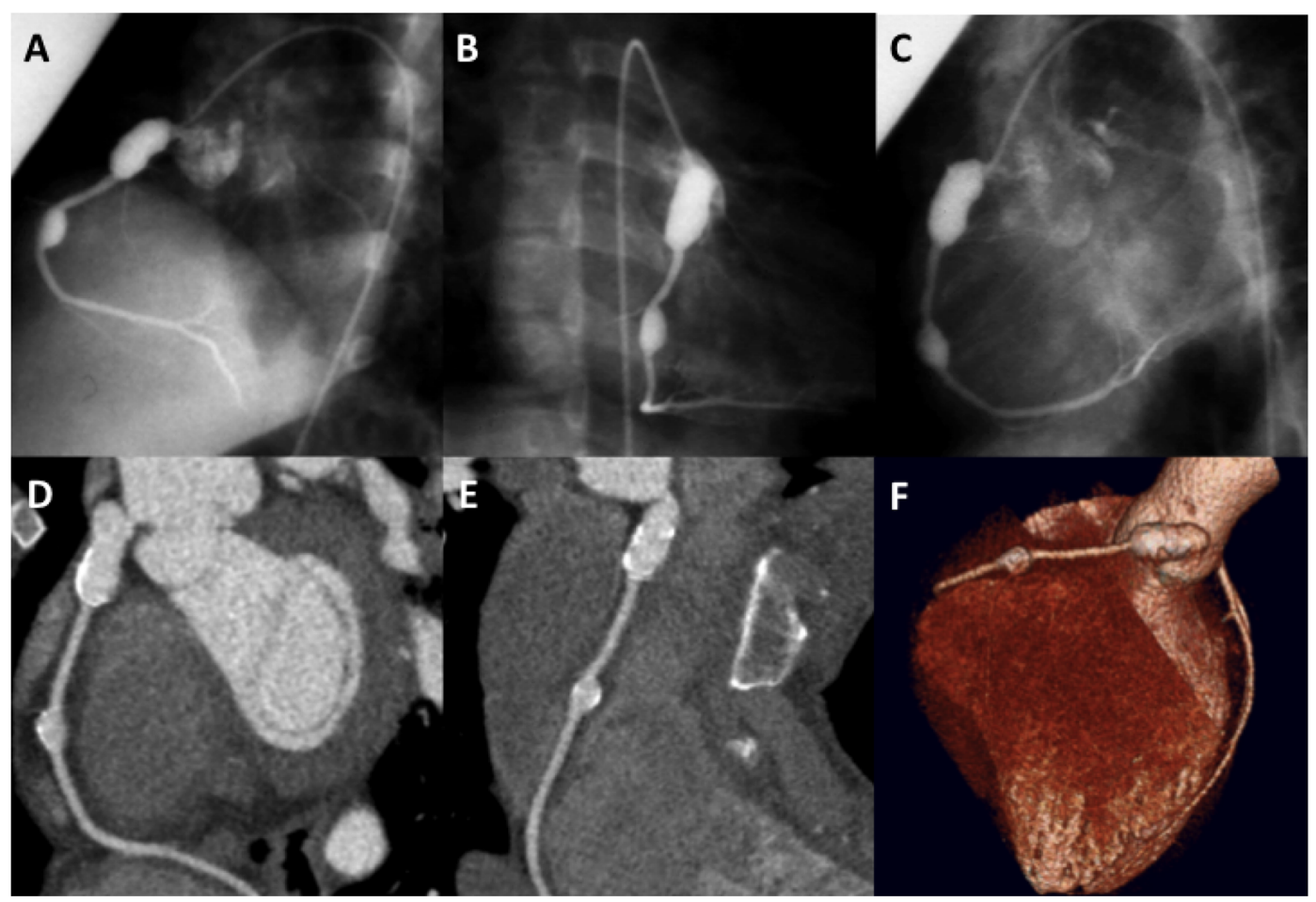

Figure 6. Cardiac CT vs catheter correlation. A-C) Conventional angiographic views display 2 giant aneurysms in the RCA. D,E) Curved multiplanar reformats from cardiac CT data set demonstrate good correlation and more clearly depict wall calcification and lack of mural thrombus. F) Volume-rendered image from a cardiac CT data set represents an alternative visual method for displaying CT findings.

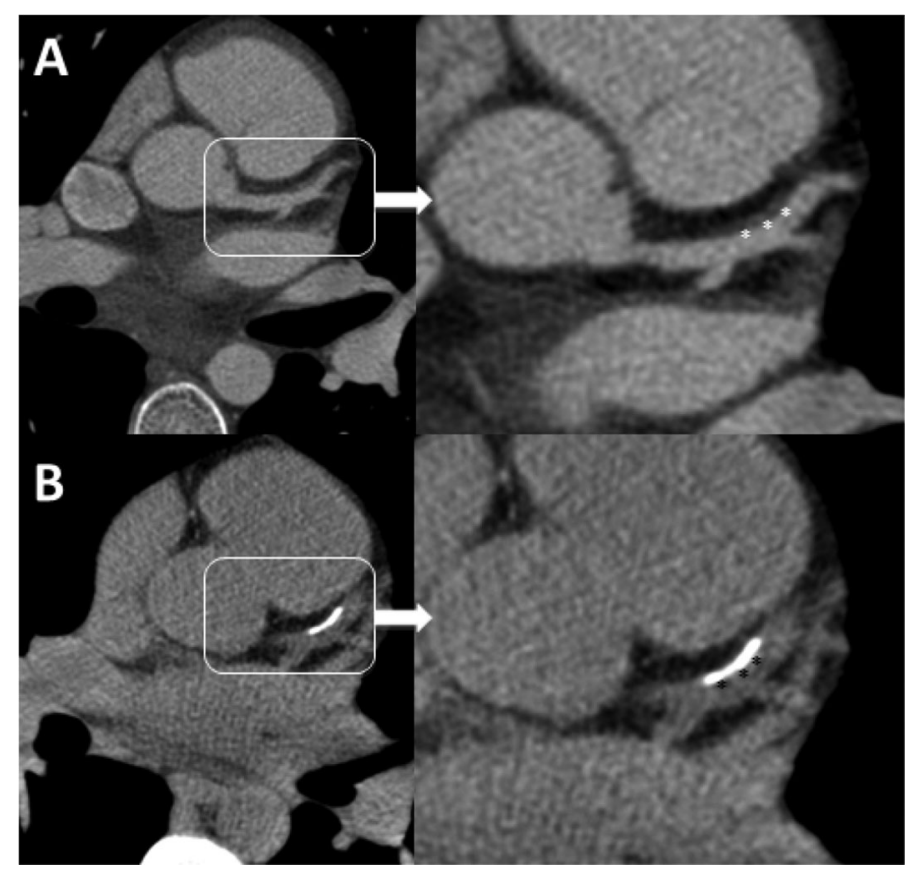

Figure 7. Progression of plaque. A) Initial coronary CT demonstrates subtle soft plaque/vessel wall thickening (white asterisks) in the proximal LAD. B) Calcium score, 3 years later, now shows new overlying calcification (black asterisks) implying mineralization secondary to chronic low-grade inflammation. Statin therapy should be considered for all KD patients although the level of evidence for treatment is weak. 


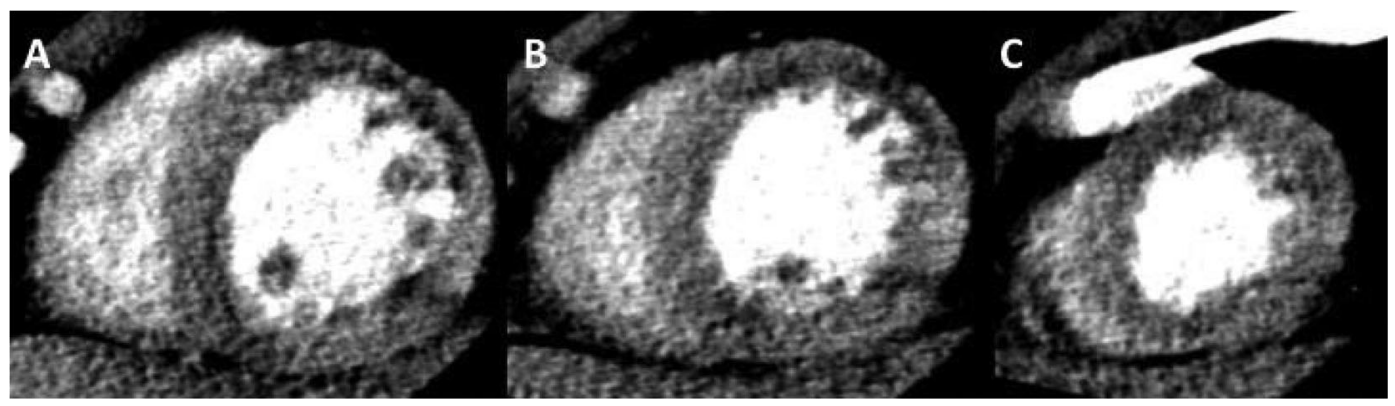

Figure 8. Dipyridamole stress CTA. A-C) Basal, mid and apical short axis reconstructions of a stress CT data set demonstrating an LAD territory perfusion defect in a Kawasaki patient with LAD aneurysm and prior occlusion.

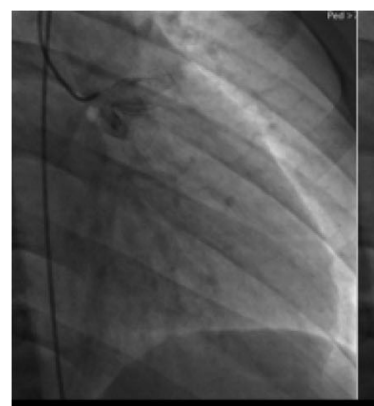

FRAME 1

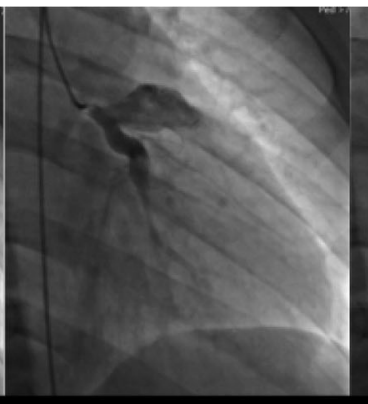

FRAME 20

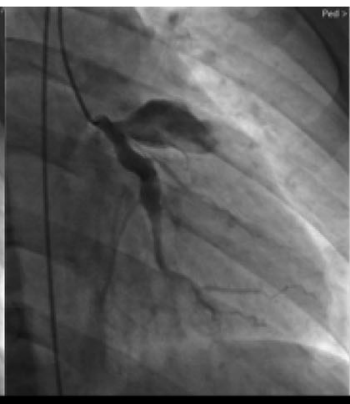

FRAME 40

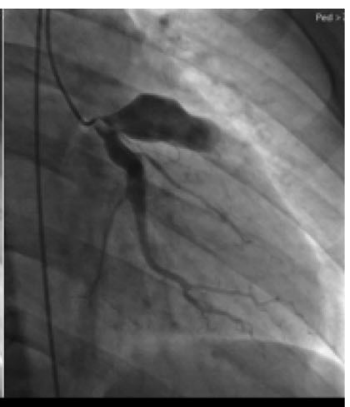

FRAME 60

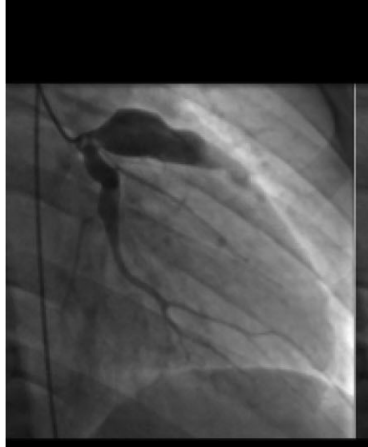

FRAME 80

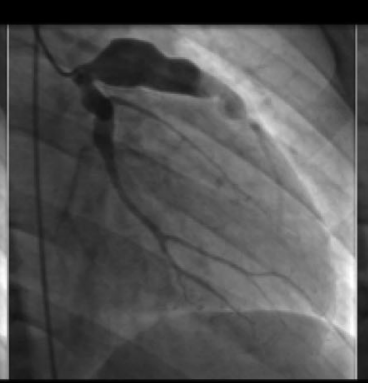

FRAME 100

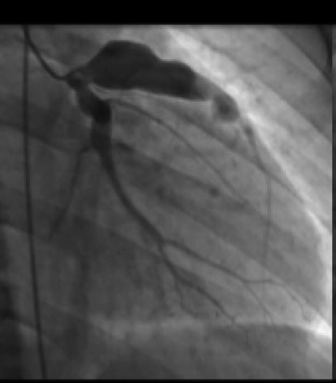

FRAME 120

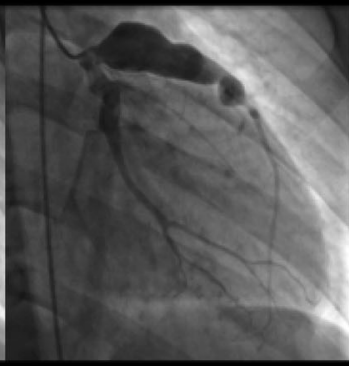

FRAME 150

Figure 9. Coronary stasis. Multiple frames are shown from the left coronary injection of a conventional angiogram. A large saccular proximal LAD aneurysm is outlined. Note the extreme delay before contrast fully opacifies the distal LAD at frame 150 from the start of injection. It is this intra-coronary stasis that accounts for the high thrombotic risk in this patient population, even on anticoagulants.

\section{Cardiac catheterization}

Coronary angiography

Angiography remains the tool of choice in symptomatic patients or those with equivocal non-invasive imaging. As a 'real-time' injection of contrast is made, the degree of sluggish or swirling flow is much more obvious than with cross-sectional techniques (Figure 9). Nonetheless, we have occasionally seen cases where swirling flow was misinterpreted as ball valve thrombus in a proximal giant aneurysm (Figure 10).

\section{Coronary intervention}

Thrombotic occlusion of the coronary artery is a feared complication in patients with KD, not only in the acute phase of illness, but also many years later. In a case series of 50 adult patients, thrombotic occlusion of the aneurysmal segment was the most common complication. The majority of the patients were treated with balloon angioplasty and/or 


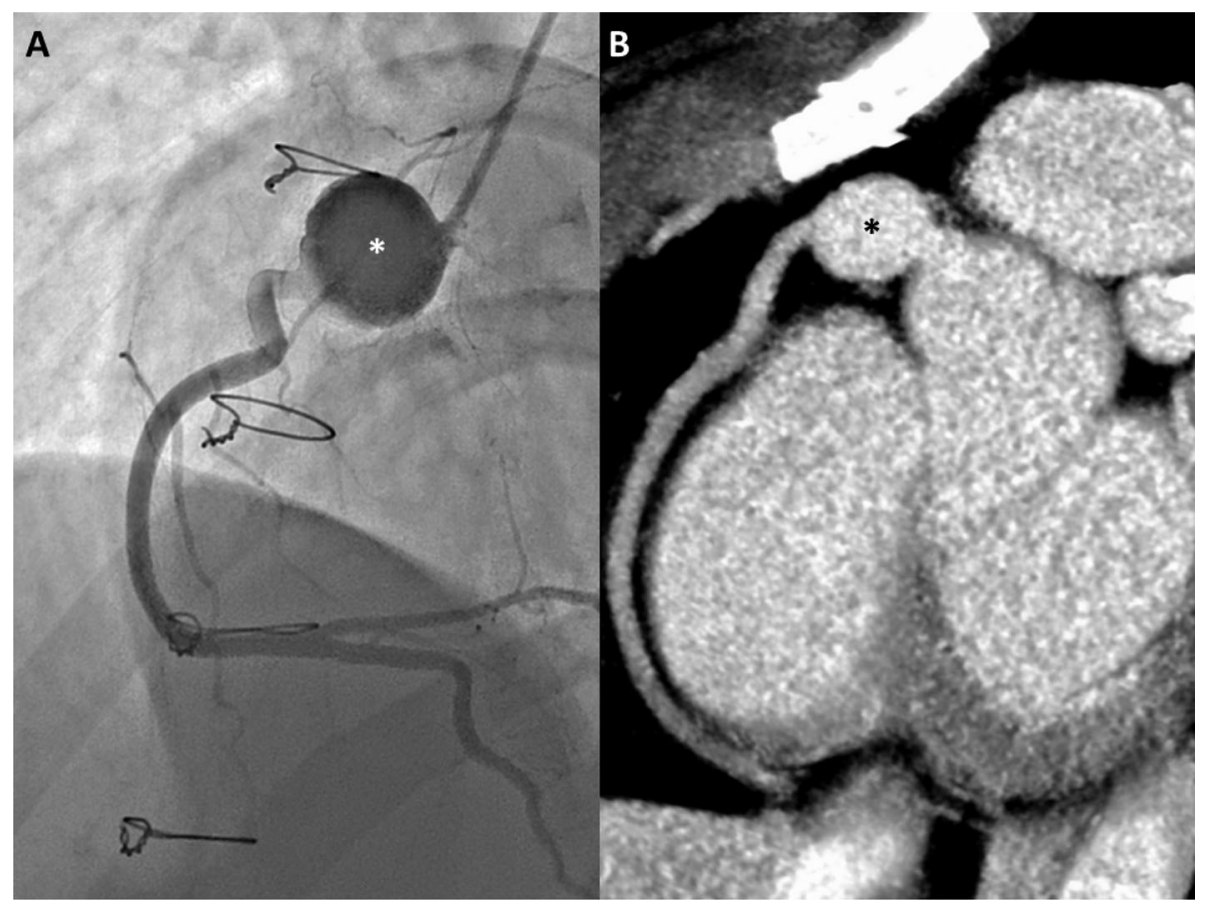

Figure 10. Pseudo-thrombus at catheterization. A) Right coronary injection demonstrates a large proximal aneurysm with an apparent central oval lucency (white asterisk). This was interpreted as a ball-valve thrombus in this young man with chest pain symptoms. B) Same-day coronary CT acquired 1 minute after injection shows completely uniform iodine intensity within the aneurysm (black asterisk), confirming the absence of any real thrombus - indicating that the catheter finding was the result of swirling flow and incomplete mixing of blood and iodine immediately after injection.

thrombolytic use; rotational atherectomy and stenting were used in only one patient each. IVUS examination in some of these patients demonstrated thickened intima, as expected, but no atherosclerotic changes were noted. ${ }^{22}$

Balloon angioplasty, even with high-pressure balloons, is unlikely to be successful in adult patients, due to presence of dense fibrosis. ${ }^{23}$ Such an approach can result in neo-aneurysm formation that has the potential to result in stent malapposition. Similarly, because of variation in vessel caliber, due to interspersed aneurysm and stenotic lesions, achieving satisfactory stent apposition can be challenging, ${ }^{24}$ and malapposed stent struts are an independent risk factor for stent thrombosis.

Percutaneous coronary intervention in patients with KD should be guided by intra-coronary imaging that can help differentiate between densely calcified lesions versus fibrotic ones, as rotational atherectomy can be successfully used to treat the former, whereas use of a cutting balloon would be preferred in the latter. ${ }^{25}$

\section{Fractional flow reserve (FFR)}

Visual assessment of coronary angiography has inherent limitations. FFR measurement has been validated and extensively used to assess physiologic significance of obstructive coronary artery disease. The presence of sequential narrowings in the same artery results in a cumulative impact on myocardial perfusion. Interestingly, not only coronary stenosis, but also aneurysmal dilatation results in 'pressure loss' due to turbulence, which may contribute towards worsening of coronary perfusion. ${ }^{26,27}$ In patients with $\mathrm{KD}$, whose coronary arteries demonstrate diffuse stenosis and aneurysmal dilatation, visual assessment by angiography alone is inadequate, and FFR should be considered. One caveat though is that FFR assessment relies on vascular endothelial response to variety of vasoactive substances. Patients with $\mathrm{KD}$ are known to have endothelial dysfunction that can affect peak hyperemia, although the impact of such dysfunction on FFR measurement is not known.

\section{IVUS, OCT}

Intravascular ultrasound (IVUS) uses piezo-electric transducer or electronic phased array to sends out sound signals that are reflected by the tissue it passes through, according to their acoustic properties. IVUS examination of the coronary 

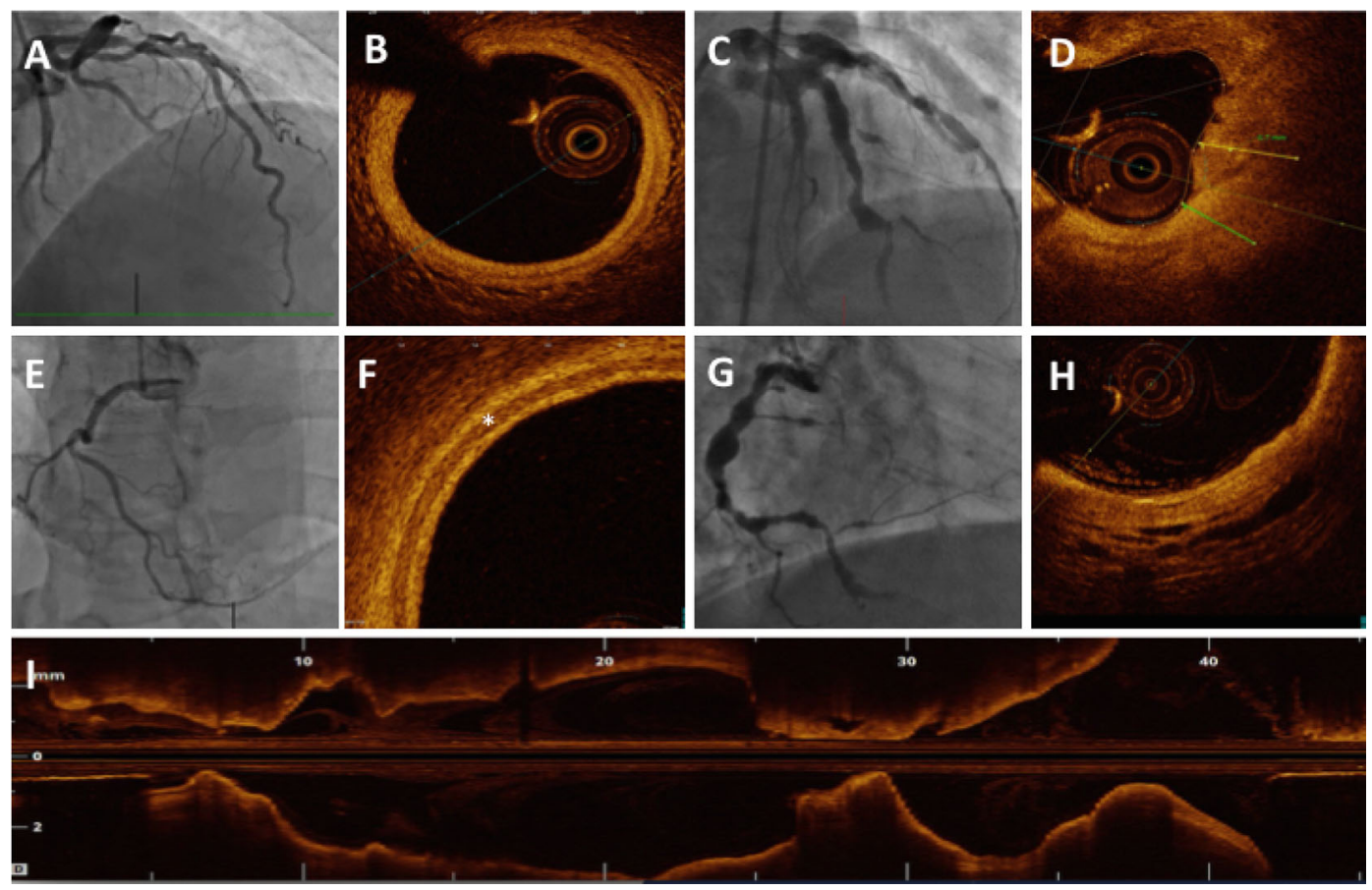

Figure 11. Optical coherence tomography. (A \& E) Coronary angiogram demonstrating mild atherosclerotic disease. (B \& F) OCT examination of these coronary arteries demonstrating normal intima-media where * demonstrates muscular media. (C \& G) Angiography demonstrating coronary arteries many years after Kawasaki disease. OCT examination of these arteries demonstrates destroyed intima-media structure that is replaced by thick fibrosis (D) and disintegrated muscular layer (H). (I) Longitudinal reformatted OCT image of the same coronary artery demonstrated aneurysmal and stenotic segments along its length.

\begin{tabular}{|c|c|}
\hline $\begin{array}{l}\text { Coronary CTA } \\
\text { - Asses coronaries - exclude aneurysm and stenosis } \\
\text { - Exclude aneurysmal thrombus }\end{array}$ & 1 \\
\hline $\begin{array}{l}\text { Treadmill stress echo } \\
\text { - Exclude ischemia and assess EF }\end{array}$ & 2 \\
\hline $\begin{array}{l}\text { Stress perfusion CMR } \\
\text { - Exclude ischemia } \\
\text { - Exclude myocardial scar } \\
\text { - Exclude aneurysmal thrombus }\end{array}$ & 2 \\
\hline $\begin{array}{l}\text { Rubidium stress PET } \\
\text { - Exclude ischemia } \\
\text { - If ischemia present, quantify as percent of myocardium } \\
\text { - Measure absolute coronary flow in } \mathrm{mls} / \mathrm{min} / \mathrm{g}\end{array}$ & ? \\
\hline $\begin{array}{l}\text { Coronary angiography } \\
\text { - Confirm stenosis suspected from non-invasive testing } \\
\text { - Consider FFR/IVUS/OCT as clinically indicated }\end{array}$ & 3 \\
\hline
\end{tabular}

Figure 12. A hierarchical approach to testing in complicated adult Kawasaki disease. Newly referred adults with a history of Kawasaki disease in childhood - are staged with up to 3 levels of investigation. Level 1: Coronary CTA is performed first. If there is no evidence of coronary involvement (or no worse than only mild dilatation), no further investigation is required. If there is evidence of aneurysm or stenosis further testing is required. Level 2: The precise test chosen should depend upon availability and local expertise. If embolic infarction from aneurysmal thrombus is suspected, then CMR is often the most revealing test. Where the selected level 2 test is equivocal, we often proceed to an alternative level 2 test for confirmation. When there remains residual doubt, or if a level 2 test is positive, we proceed to the next step. Level 3: Invasive coronary angiography with or without hemodynamic assessment of severity of stenosis by FFR. While OCT and IVUS may be useful to assess stent deployment, percutaneous coronary intervention is often a poorer choice than bypass surgery for the majority of Kawasaki patients, given the variability in cross-sectional diameter of involved segments. 
arteries, many years after an acute episode of KD often demonstrates thickened intima-media complex, and diffuse calcification at the sites of persisting or regressed aneurysms, but atherosclerotic changes are not usually seen. ${ }^{28}$

Optical coherence tomography (OCT) measures backscatter of the light (optical echos), and offers the highest possible resolution images below $10 \mu \mathrm{m}$ (Figure 11). OCT examination allows higher definition image acquisition of a fibrous cap (thickness, cellular infiltration and erosion), necrotic core, calcified lesions, plaque rupture, dissection plane, and stent apposition. ${ }^{29,30}$ These images are much clearer than the ones acquired with IVUS. OCT examination provides detailed tissue information, comparable with the histopathological examination of the coronary arteries. ${ }^{31}$ However, higher resolution comes at a cost of limited penetration; OCT may not be an imaging modality of choice in large or giant aneurysms.

\section{Conclusions}

Kawasaki disease patients with known coronary involvement should be followed carefully throughout adult life. A single approach is unlikely to be able to reliably demonstrate all of the possible coronary and cardiac complications that can result from this disease. Appropriate use of imaging allows for early detection of complications with subsequent surveillance and may reduce subsequent morbidity and mortality.

\section{References}

1. Newburger JW, Takahashi M, Gerber MA, et al.: Diagnosis, treatment, and long-term management of Kawasaki disease: a statement for health professionals from the Committee on Rheumatic Fever, Endocarditis and Kawasaki Disease, Council on Cardiovascular Disease in the Young. Circulation. 2004 Oct 26; 110(17): 2747-2771.

PubMed Abstract | Publisher Full Text

2. Sengupta D, Kahn AM, Burns JC, et al.: Image-based modeling of hemodynamics in coronary artery aneurysms caused by Kawasaki disease. Biomech Model Mechanobiol. 2012 Jul; 11(6): 915-932.

PubMed Abstract | Publisher Full Text | Free Full Text

3. Dhillon $\mathrm{R}$, Clarkson $\mathrm{P}$, Donald $\mathrm{AE}$, et al.: Endothelial dysfunction late after Kawasaki disease. Circulation. 1996 Nov 1; 94(9): 2103-2106.

PubMed Abstract | Publisher Full Text

4. McCandless RT, Minich LL, Wilkinson SE, et al.: Myocardial strain and strain rate in Kawasaki disease. Eur Heart J Cardiovasc Imaging. 2013 Nov; 14(11): 1061-1068.

PubMed Abstract | Publisher Full Text

5. Yu W, Wong SJ, Cheung Y: Left ventricular mechanics in adolescents and young adults with a history of kawasaki disease: analysis by three-dimensional speckle tracking echocardiography. Echocardiography. 2014 Apr; 31(4): 483-491. PubMed Abstract | Publisher Full Text

6. Mostafa MS, Sayed AO, Al Said YM: Assessment of coronary ischaemia by myocardial perfusion dipyridamole stress technetium-99 m tetrofosmin, single-photon emission computed tomography, and coronary angiography in children with Kawasaki disease: pre- and post-coronary bypass grafting. Cardiol Young. 2015 Jun; 25(5): 927-934. PubMed Abstract | Publisher Full Text

7. Mc Ardle BA, Dowsley TF, deKemp RA, et al.: Does rubidium-82 PET have superior accuracy to SPECT perfusion imaging for the diagnosis of obstructive coronary disease?: A systematic review and meta-analysis. J Am Coll Cardiol. 2012 Oct 30; 60(18): 1828-1837.

PubMed Abstract | Publisher Full Text

8. Parker MW, Iskandar A, Limone B, et al.: Diagnostic accuracy of cardiac positron emission tomography versus single photon emission computed tomography for coronary artery disease: a bivariate meta-analysis. Circ Cardiovasc Imaging. 2012 Nov; 5(6): 700-707.

PubMed Abstract | Publisher Full Text

9. Muzik O, Paridon SM, Singh TP, et al.: Quantification of myocardial blood flow and flow reserve in children with a history of kawasaki disease and normal coronary arteries using positron emission tomography. J Am Coll Cardiol. 1996; 28: 757-762. Publisher Full Text

10. Hauser M, Bengel F, Kuehn A, et al.: Myocardial blood flow and coronary flow reserve in children with "normal" epicardial coronary arteries after the onset of Kawasaki disease assessed by positron emission tomography. Pediatr Cardiol. 2004 Apr; 25(2): 108-112.

PubMed Abstract | Publisher Full Text

11. Furuyama $\mathrm{H}$, Odagawa $\mathrm{Y}$, Katoh $\mathrm{C}$, et al.: Assessment of coronary function in children with a history of Kawasaki disease using (15)O-water positron emission tomography. Circulation. 2002 Jun 18; 105(24): 2878-2884. PubMed Abstract | Publisher Full Text

12. Cicala S, Pellegrino T, Storto G, et al.: Noninvasive quantification of coronary endothelial function by SPECT imaging in children with a history of Kawasaki disease. Eur J Nucl Med Mol Imaging. 2010 Dec; 37(12): 2249-2255.

PubMed Abstract | Publisher Full Text

13. Spiliotopoulos K, Yanagawa B, Crean A, et al.: Surgical management of a left anterior descending pseudoaneurysm related to Behcet's disease. Ann Thorac Surg. 2011 Mar; 91(3): 912-914.

PubMed Abstract | Publisher Full Text

14. Tobler D, Motwani M, Wald RM, et al.: Evaluation of a comprehensive cardiovascular magnetic resonance protocol in young adults late after the arterial switch operation for d-transposition of the great arteries. J Cardiovasc Magn Reson. 2014 Dec 11; 16: 98.

2014 Dec 11; 16: 98.
PubMed Abstract | Publisher Full Text | Free Full Text

15. Deva DP, Torres FS, Wald RM, et al.: The value of stress perfusion cardiovascular magnetic resonance imaging for patients referred from the adult congenital heart disease clinic: 5-year experience at the Toronto General Hospital. Cardiol Young. 2014 Oct; 24(5): 822-830. PubMed Abstract | Publisher Full Text

16. Greenwood JP, Maredia N, Younger JF, et al.: Cardiovascular magnetic resonance and single-photon emission computed tomography for diagnosis of coronary heart disease (CE-MARC): a prospective trial. Lancet. 2012 Feb 4; 379(9814): 453-460. PubMed Abstract | Publisher Full Text | Free Full Text

17. Yu Y, Sun K, Wang R, et al.: Comparison study of echocardiography and dual-source CT in diagnosis of coronary artery aneurysm due to Kawasaki disease: coronary artery disease. Echocardiography. 2011 Oct; 28(9): 1025-1034. PubMed Abstract | Publisher Full Text

18. Carbone I, Cannata D, Algeri E, et al.: Adolescent Kawasaki disease: usefulness of 64-slice CT coronary angiography for follow-up investigation. Pediatr Radiol. 2011 Sep; 41(9): 1165-1173. PubMed Abstract | Publisher Full Text

19. Kahn AM, Budoff MJ, Daniels LB, et al.: Calcium scoring in patients with a history of Kawasaki disease. JACC Cardiovasc Imaging. 2012 Mar; 5(3): 264-272. PubMed Abstract | Publisher Full Text | Free Full Text

20. de Agustin JA, Gomez de Diego JJ, Rodrigo JL, et al.: Right coronary artery aneurysm due to Kawasaki disease: A comprehensive assessment by multislice computed tomography. Int J Cardiol. 
2014 May; 173(2): e12-e13.

PubMed Abstract | Publisher Full Text

21. Rochitte $\mathrm{CE}$, George RT, Chen MY, et al.: Computed tomography angiography and perfusion to assess coronary artery stenosis causing perfusion defects by single photon emission computed tomography: the CORE320 study. Eur Heart J. 2014 May; 35(17): 1120-1130.

PubMed Abstract | Publisher Full Text | Free Full Text

22. Tsuda E, Abe T, Tamaki W: Acute coronary syndrome in adult patients with coronary artery lesions caused by Kawasaki disease: review of case reports. Cardiol Young. 2011 Feb; 21(1): 74-82.

PubMed Abstract | Publisher Full Text

23. Sugimura $\mathrm{T}$, Yokoi $\mathrm{H}$, Sato $\mathrm{N}$, et al.: Interventional treatment for children with severe coronary artery stenosis with calcification after long-term Kawasaki disease. Circulation. 1997 Dec 2; 96(11): 3928-3933.

PubMed Abstract | Publisher Full Text

24. Shah $\mathrm{AH}$, Abdel-Hadi $\mathrm{H}$, Overgaard $\mathrm{CB}$, et al.: Kawasaki disease and coronary intervention: A word of caution. Int J Cardiol. 2015 Dec; 201: 646-647.

PubMed Abstract | Publisher Full Text

25. Ito S, Suzuki T, Suzuki T: Adjunctive use of cutting balloon after rotational atherectomy in a young adult with probable kawasaki disease. J Invasive Cardiol. 2003. PubMed Abstract

26. Murakami T, Tanaka N: The physiological significance of coronary aneurysms in Kawasaki disease. EuroIntervention; 2011; 944-947. Publisher Full Text

27. Yoshikawa T, Suma K, Sugawara M: Hemodynamic effects of beadshaped aneurysm in Kawasaki's disease (author's transl). Kokyu to junkan Respiration. 1980.

28. Suzuki A, Yamagishi M, Kimura K: Functional behavior and morphology of the coronary artery wall in patients with Kawasaki disease assessed by intravascular ultrasound. J Am Coll Cardiol. 1996; 27: 291-296.

Cardiol. 1996; 27: 291-296.
PubMed Abstract | Publisher Full Text

29. Finn AV, Chandrashekhar Y, Narula J: IVUS and OCT: either or survivor ... 2011.

30. Suter MJ, Nadkarni SK, Weisz G, et al.: Intravascular optical imaging technology for investigating the coronary artery. JACC Cardiovasc Imaging. 2011 Sep 1; 4(9): 1022-1039.
PubMed Abstract | Publisher Full Text | Free Full Text

31. Bezerra HG, Costa MA, Guagliumi G, et al.: Intracoronary optical coherence tomography: a comprehensive review clinical and research applications. JACC Cardiovasc Interv. 2009 Nov; 2(11): 1035-1046.

PubMed Abstract | Publisher Full Text | Free Full Text 


\section{Open Peer Review}

\section{Current Peer Review Status: ? $\checkmark$}

\section{Version 1}

Reviewer Report 23 March 2023

https://doi.org/10.5256/f1000research.76721.r163155

(C) 2023 Pilania R. This is an open access peer review report distributed under the terms of the Creative Commons Attribution License, which permits unrestricted use, distribution, and reproduction in any medium, provided the original work is properly cited.

\section{Rakesh Kumar Pilania}

Department of Pediatrics, Institute of Medical Education and Research, Chandigarh, 160012, India

Crean et al. have submitted their review of imaging the delayed complications of childhood KD. Authors have provided comprehensive review on the subject. However, I have few comments.

1. Echo:

1. Author should define difference between dilatation, ectasia, and aneurysms clearly for benefit of readers. Authors can add images of echocardiography differentiating among these terminologies.

2. Though ECHO may be an initial modality of imaging at presentation, however as the child grows ECHO may be challenging due to smaller acoustic window, inability to demonstrate the CAAs in mid and distal segments and LCX. complications like thrombus. stenosis or mural calcifications.

3. Ectasia is confusing terminology and nowadays not very common in use.

4. Limitations of Echo need to be talked upon, especially identification of distal aneurysms, thrombosis, stenosis, calcifications.

2. Nuclear scan: Role of nuclear imaging is need to be balanced in current era where CTCA, $\mathrm{ECHO}$ and CMR would be more important imaging.

3. CMR: CMR is most useful imaging modality in the late phase of disease. Authors have detailed almost very aspect of that. However, Article is silent on MRCA. Role of MRCA needs more literature search and its role and comparison with CTCA.

4. Cardiac CT:

1. CTCA is definitely an imaging of choice for evaluation in an adult with history of KD.

2. It would be important to highlight the strengths of CTCA in comparison to 2D-Echo in 
identification of distal coronary artery involvement, entire course of coronaries, LCX, complications, stenosis etc. Singhal $\mathrm{M}$ et al. Distal coronary artery abnormalities in Kawasaki disease: experience on CT coronary angiography in 176 children $^{1}$.

3. Radiation exposure optimization protocol.

4. Authors describe CTCA as gate keeper modality: to be elaborated further

5. Detection of calcification need to be more highlighted. Chakraborty R, et al. Coronary arterial abnormalities detected in children over 10 years following initial Kawasaki disease using cardiac computed tomography ${ }^{2}$.

5. Cardiac cath: authors have identified very specific indications for cath angio in a given patient with KD.

6. Authors have provided imaging approach in a complicated patient with KD. This figure is not cited in text. It would be better to expand on that before conclusions section with separate subheading. Authors have given equal weightage to rubidium stress PET to stress perfusion CMR and treadmill stress ECHO. As rubidium stress PET would have associated exposure with radiation exposure. Author can justify their approach.

7. Minor errors: Author can use consistently use abbreviation for Kawasaki disease as KD throughout the manuscript. Please check spacing and abbreviations throughout the manuscript.

\section{References}

1. Singhal M, Pilania RK, Jindal AK, Gupta A, et al.: Distal coronary artery abnormalities in Kawasaki disease: experience on CT coronary angiography in 176 children.Rheumatology (Oxford). 2023; 62 (2): 815-823 PubMed Abstract | Publisher Full Text

2. Chakraborty R, Singhal M, Pandiarajan V, Sharma A, et al.: Coronary arterial abnormalities detected in children over 10 years following initial Kawasaki disease using cardiac computed tomography.Cardiol Young. 2021; 31 (6): 998-1002 PubMed Abstract | Publisher Full Text

Is the topic of the review discussed comprehensively in the context of the current literature?

Partly

Are all factual statements correct and adequately supported by citations?

Yes

Is the review written in accessible language?

Yes

Are the conclusions drawn appropriate in the context of the current research literature? Partly 
Competing Interests: No competing interests were disclosed.

Reviewer Expertise: Kawasaki disease

I confirm that I have read this submission and believe that I have an appropriate level of expertise to confirm that it is of an acceptable scientific standard, however I have significant reservations, as outlined above.

Reviewer Report 23 December 2022

https://doi.org/10.5256/f1000research.76721.r154822

(C) 2022 Hsieh K. This is an open access peer review report distributed under the terms of the Creative Commons Attribution License, which permits unrestricted use, distribution, and reproduction in any medium, provided the original work is properly cited.

\section{Kai Sheng Hsieh}

Children's Hospital and School of Medicine, China Medical University, Taichung, Taiwan

This manuscript discussed the imaging modalities in the late phase of childhood Kawasaki disease. The authors thoroughly reviewed the role of echocardiography, nuclear perfusion imaging, positron emission tomography, computed tomography, cardiovascular magnetic resonance angiography, coronary artery angiography and intervention, coronary fractional flow low reserve, intravascular ultrasound, and optical coherence tomography (SPECT/PET/CT/CMRAngiography/CAG/CFFR/IVUS/OCT). The review is comprehensive and informative. The quality of various figures also are good. The authors also list a table to display the relative strengths and weaknesses of commonly used imaging modalities for Kawasaki disease. The content of this manuscript is thus of sufficient quality and I will suggest to index this manuscript as its current form and no revision is necessary.

Is the topic of the review discussed comprehensively in the context of the current literature?

Yes

Are all factual statements correct and adequately supported by citations?

Yes

Is the review written in accessible language?

Yes

Are the conclusions drawn appropriate in the context of the current research literature? Yes

Competing Interests: No competing interests were disclosed.

Reviewer Expertise: Pediatric Cardiology, echocardiography, Pediatric cardiac imaging 


\section{I confirm that I have read this submission and believe that I have an appropriate level of expertise to confirm that it is of an acceptable scientific standard.}

Reviewer Report 10 June 2022

https://doi.org/10.5256/f1000research.76721.r136684

(C) 2022 van Stijn D. This is an open access peer review report distributed under the terms of the Creative Commons Attribution License, which permits unrestricted use, distribution, and reproduction in any medium, provided the original work is properly cited.

\section{Diana van Stijn}

Department of Pediatric Immunology, Rheumatology, and Infectious Diseases, Emma Children's Hospital, Amsterdam UMC, University of Amsterdam, Amsterdam, The Netherlands

Andrew et al. have submitted "Imaging the delayed complications of childhood Kawasaki disease". The aim of this paper is to discuss imaging modalities used in Kawasaki disease patients during adolescence and adult life. First of all we would like to appraise the enormous effort in performing this hands-on review. Knowledge on cardiovascular imaging in adults and young adults with a history of Kawasaki disease is of great importance.

\section{Minor comments:}

\section{Overall}

The authors may consider giving a bit more in-depth background information on the risks that come hand-in-hand with developing CAA after Kawasaki disease (mostly in patients with persistent giant aneurysms). Moreover, it would be nice to add some information on size-dependent longterm risk of having a small, medium and giant CAA. Also, few references are used throughout the article. Although the article discusses very useful expert opinions, it would be nice to add some references with supporting data (from this or other research groups) as well.

\section{Abstract}

We would strongly recommend using the term "imaging modalities" instead of "imaging surveillance". As imaging surveillance might suggest a hands-on flowchart of the desired imaging over time during follow-up. While the strength of this review lies more in depicting the potential of visualizing pathology with specific imaging modalities.

\section{Introduction}

"Coronary arterial complications, both in acute or chronic phase of the illness, result in high morbidity and mortality." This sentence might give the impression that Kawasaki disease has a high morbidity and mortality. Please consider rephrasing this sentence and add absolute numbers and references with the risk of developing persistent CAA and consequent complications (such as thrombosis, myocardial infarction etc.).

\section{Introduction section "echocardiography"}

The authors mention "perivascular echogenicity or "brightness"" as important imaging features on 
echocardiography. Despite that early reports considered this as an early sign in KD ${ }^{1}$, recent papers showed this to be a non-specific finding that can also be found in children without KD 2,3. Do the authors consider perivascular brightness an important hallmark in the (young) adult population, or is it as questionable as it is during early childhood?

"Echocardiography is always the initial tool in the assessment of the patient with Kawasaki disease. Young children generally have excellent echocardiographic windows with the proximal sections of the coronary arteries being fully visualized." Add references indicating that we don't miss proximal CAA. The authors might also consider discussing whether (or how often) distal CAA may be missed by echocardiography?

"Valvular involvement in Kawasaki disease is reported but is rarely a prominent feature. Nonetheless the presence of severe mitral regurgitation should raise the question of underlying myocardial ischemia and secondary papillary muscle dysfunction." Please add references.

\section{4. $C M R$}

"Nonetheless, qualitative perfusion imaging in Kawasaki Disease can be problematic" A typo: Kawasaki Disease not Kawasaki disease. In the last few paragraphs many statements are made without references, please add references.

\section{Cardiac CT}

The authors mention something very important for the transition to adult care, namely "staging" new referrals by performing a CT. Would the authors, based on their expert opinion, advise pediatricians/pediatric cardiologists prior to referring a young adult to adult care, to perform a CT?

“Cardiac CT is a useful and reasonable method for 'staging' new referrals to the adult Kawasaki clinic. In our clinic it is a baseline test to establish the presence and extent of aneurysmal disease and stenosis and may act as a gatekeeper to subsequent coronary angiography." When do authors recommend using cardiac CT in the pediatric population?

Please consider discussing radiation exposure as a disadvantage of CT as well.

Several statements are made without references, for example:

"The major advantages of cardiac CT are its rapidity, spatial resolution, and sensitivity for calcium. Modern scanners can complete acquisition of the target anatomy in a few seconds (or less) making CT very suitable for the restless or claustrophobic. Spatial resolution is in the region of 0.5 $\mathrm{mm}$ for most scanners which is adequate for the depiction of aneurysms, thrombus and normal or ecstatic coronary segments."

\section{Figure 12}

This figure is of great value, knowing the scope of this article is more towards the value of imaging modalities and not so much surveillance. Could you still elaborate on how often you recommend to perform level 3 imaging? In children we tend to refrain from invasive coronary artery angiography and solely use it when intervention is needed. Therefore we perform follow-up mainly with level $1 \& 2$ in KD patients (with coronary artery involvement).

\section{References}

1. Takahashi M, Mason W, Acherman R, Lewis A, et al.: Is Perivascular Echo Brightness a Reliable 
Marker of Coronary Arteritis in Acute Kawasaki Syndrome?. Pediatric Research. 2003; 53 (1).

Publisher Full Text

2. Rabinowitz EJ, Rubin LG, Desai K, Hayes DA, et al.: Examining the Utility of Coronary Artery Lack of Tapering and Perivascular Brightness in Incomplete Kawasaki Disease.Pediatr Cardiol. 2019; 40

(1): 147-153 PubMed Abstract | Publisher Full Text

3. Yu JJ, Jang WS, Ko HK, Han MK, et al.: Perivascular brightness of coronary arteries in Kawasaki disease.J Pediatr. 2011; 159 (3): 454-457.e1 PubMed Abstract | Publisher Full Text

Is the topic of the review discussed comprehensively in the context of the current literature?

Yes

Are all factual statements correct and adequately supported by citations?

Yes

Is the review written in accessible language?

Yes

Are the conclusions drawn appropriate in the context of the current research literature? Yes

Competing Interests: No competing interests were disclosed.

Reviewer Expertise: Kawasaki disease with focus on cardiovascular pathology and imaging

I confirm that I have read this submission and believe that I have an appropriate level of expertise to confirm that it is of an acceptable scientific standard, however I have significant reservations, as outlined above.

The benefits of publishing with F1000Research:

- Your article is published within days, with no editorial bias

- You can publish traditional articles, null/negative results, case reports, data notes and more

- The peer review process is transparent and collaborative

- Your article is indexed in PubMed after passing peer review

- Dedicated customer support at every stage

For pre-submission enquiries, contact research@f1000.com

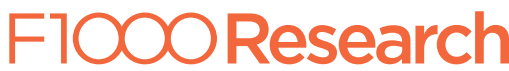

